\title{
The Effects of Risk Culture on Organisational Performance - The Cases of Some Selected Financial Institutions in Ghana
}

\author{
Benjamin Kpodo ${ }^{1}$, Kofi Agyekum ${ }^{2}$ \\ ${ }^{1}$ School of Graduate Studies, Kwame Nkrumah University of Science and Technology, Kumasi, Ghana \\ ${ }^{2}$ Department of Building Technology, Kwame Nkrumah University of Science and Technology, Kumasi, Ghana
}

\begin{abstract}
The relationship between risk culture and organisational performance has engaged the attention of researchers after the Global Financial Crisis of 2008. Extant studies on risk culture and organisation performance suggest risk culture has an effect on organisational performance. Unfortunately these studies are few and are concentrated on developed countries. Relying on the Financial Stability Board's (FSB) risk culture model, due to its comprehensive coverage of all factors contributing to an effective risk management in an organisation as well as its simplicity, this study examined the relationship between risk culture and business performance in Ghana which is a developing country. Organisational performance was examined using both financial and nonfinancial measures. All factors of the two main variables of risk culture and organisational performance were measured using the FivePoint Likert Scale and were analysed using descriptive statistical measures. The data was obtained from the nineteen (19) banks listed on the Ghana Club 100 representing about 70\% of the total market share of the Ghanaian Banking Industry, with both local and foreign origins. The analysis was based on 19 completed questionnaires, one (1) each from each respondent and interview responses from eleven (11) respondents. Individual respondents were purposively selected from risk related departments within the banks. The study revealed that there was no significant differences among the banks in terms of the risk culture determinants and organisational performance measures. In all cases, leadership action or inaction was identified as the attribute with the strongest potential for affecting the development an effective risk culture. Overall, there was a positive correlation between Risk Culture and Organisational Performance in the Banking Industry in Ghana. Finally, a generic Risk Culture Framework (RCF) was developed to facilitate the development of effective risk cultures across all organisations.
\end{abstract}

Keywords: Enterprise Risk Management, Risk Culture, Organisational Performance, Performance Measurement, Determinants of Risk Culture, Risk Culture Framework

\section{Introduction}

\subsection{Background of Study}

The aftermath of the Global Financial Crisis (GFC) which occurred in 2008, is the emphasis on risk management as a holistic business management practice due to systemic nature of the failures which affected the organisations involved in the crisis (Walker, 2009; EC, 2010). This holistic approach to risk management in businesses referred to as Enterprise Risk Management (ERM) has received a lot of attention in recent times as businesses seek to build resilience to future crisis (Institute of Risk Management, IRM, 2012).

Consulting firms and the academic community are leading the way in establishing ERM as a distinct business practice and an academic discipline. Consulting firms all over the world have departments dedicated to providing ERM services to clients. Universities have also developed relevant courses to establish ERM as an emerging academic discipline. An example in Ghana is the introduction of Business Consulting and ERM course by the Institute of Distance Learning (IDL) of the Kwame Nkrumah University of Science and Technology (KNUST). Increasingly, many businesses are implementing ERM programmes in response to regulatory requirements and as a measure to safeguard their operations from future vicissitudes in the global economy. Risk management and for that matter ERM is a rapidly developing discipline. (Association of Insurance and Risk Managers in Industry and Commerce, AIRMIC, National Forum for Risk Management in the Public Sector, ALARM, and IRM, 2002).

The main idea of an ERM programme is to influence the culture of the business which ultimately affects its value or performance. The success therefore of an ERM programme is how well it builds the company behaviours and processes which facilitate the identification, assessment and management of risks in relation to the company's compliance, operational, financial and strategic objectives (PricewaterhouseCoopers, PwC, 2009). The aggregation of these behaviours is what is known as the risk culture of the organisation.

The Basel Committee (2011) describes risk culture as the collective set of individual and corporate values, attitudes, competencies and behaviour that demonstrates a firm's risk management approach. According to the IRM (2012) risk culture describes the risk management values, beliefs, knowledge and understanding that is common to an entity (employees, teams or groups within an organisation) with a shared purpose. This is applicable to all organisations whether private, public or not-for-profits irrespective of their geographical location. It is therefore obvious to conclude that the promotion of an effective risk culture in an organisation is conceivably the most essential tool for successful risk management (Institute of International Finance, 2008). Thus, 


\section{International Journal of Science and Research (IJSR) \\ ISSN (Online): 2319-7064 \\ Index Copernicus Value (2013): 6.14 | Impact Factor (2014): 5.611}

risk culture should be the right measurement of the effectiveness of organisation's ERM programme.

Risk culture according to the IRM enhances the concept of organisational culture to concentrate mainly on the common capacity to manage risk. The failure of the organisations at the centre of the GFC and many other organisational failures can be attributed to weak risk cultures (Ashby et al., 2012). The authors concluded that the problems of global financial crisis arose because of weak risk cultures.

Evidence from literature and examples from the business community as in the case of Lehman Brothers and the recent London Interbank Offered Rate (LIBOR) scandal, lend credence to the argument that organisational performance and in fact the survival of organisations is directly related to their risk culture (Parliamentary Commission on Banking Standards, 2013a and Ashby, 2011). Various studies concluded that effective risk management or strong risk culture increases a firm's performance (Hoyt et al., 2006; Nocco and Stulz, 2006). The terms risk management, ERM and risk culture are relatively new to businesses in Ghana. This however does not mean risk culture is totally alien to companies in Ghana. What is lacking is research on the risk culture in Ghanaian companies and how these cultures affect organisational performance. This research seeks to offer insight into the risk cultures of businesses in Ghana and how these cultures affect the performance of the businesses. It will also highlight the challenges and opportunities for Ghanaian companies in developing strong risk cultures that drive organisational performance.

\subsection{Problem Statement}

Following the GFC in 2008, there has been a lot more focus on enhancing the overall performance of organisations. The Walker Report on the corporate governance of banks in the United Kingdom (UK) concluded that behaviour and culture played a key role in the failures (Walker, 2009). Sants (2010) also noted that the GFC brought to the fore the shortcomings in governance and risk management and their underlying culture and ethics. According to Waddock (2005), the collapse of Enron, Arthur Anderson, WorldCom and Tyco International all of the United States and others across the world, can be attributed to weak risk management cultures. Risk culture must therefore be taken seriously by any entity that wants to increase its performance. Evidence from the failed companies cited above suggests there is the need for businesses anywhere in the world including Ghana to be resilient or have strong risk management cultures in order to play the critical role as the engine of growth to the next economic level.

It is important to note that various reports and enquiries such as the Walker report and the European Commission (Walker, 2009 and EC, 2010) sought to draw a relationship between risk culture and organisational performance. However, available evidence suggests that none of the above cited reports or prior studies was able to measure the actual effect of risk culture on organisational performance.

Finally, in Ghana no prior work has been identified on risk culture and its relationship with organisational performance. Thus, understanding what risk culture meant to Ghanaian companies and developing a framework to assess its effects on organisational performance will be a valuable addition to knowledge.

\subsection{Research Objectives}

The principal aim of the research project was to study the various determinants or measures of risk culture and organisational performance in Ghana and establish the relationship between risk culture and organisational performance.

To achieve the above aim, the following specific objectives were outlined:

1. To identify the key components or determinants of risk culture and organisational performance;

2. To explore the underlying challenges to developing effective risk cultures in Ghanaian companies;

3. To establish the relationship between risk culture and organisational performance and

4. To develop a generic framework to improve risk culture in businesses in Ghana.

\section{Theoretical Framework}

Presented below is a tabular representation of the various theories that undergird the research and their implication. The table summarises the theoretical construct of each theory and provides their implication for the study

Table 1: Summary of Theoretical Constructs and Implications

\begin{tabular}{|c|c|c|}
\hline Theory & Summary of Construct & Implication for Study \\
\hline $\begin{array}{c}\text { Culture } \\
\text { theory }\end{array}$ & $\begin{array}{c}\text { Organisational practices and behaviours that are } \\
\text { expected, valued and supported through its operations. } \\
\text { (Röschmann, 2014) Sheedy \& Griffin (2014) }\end{array}$ & $\begin{array}{c}\text { Risk culture can be defined in the light of the organisation's } \\
\text { operations. These operations can be seen in the light of tone at the } \\
\text { top or leadership example, prevailing accountability framework, } \\
\text { effective challenge and compensation or reward system. }\end{array}$ \\
\hline $\begin{array}{c}\text { Organisation } \\
\text { al theory }\end{array}$ & $\begin{array}{c}\text { Culture influences all aspects of organisational life. } \\
\text { (Schein, 2012) }\end{array}$ & $\begin{array}{c}\text { This influence could help establish the relationship between risk } \\
\text { culture and performance of the organisation. }\end{array}$ \\
\hline $\begin{array}{c}\text { Agency } \\
\text { theory }\end{array}$ & $\begin{array}{c}\text { Agency relation comes into being because of the } \\
\text { separation of ownership and control. } \\
\text { (Jensen \& Meckling, 1976) }\end{array}$ & $\begin{array}{c}\text { Owners or principals therefore need to rely on the control } \\
\text { mechanism in place to achieve their objectives. This control } \\
\text { environment could be equated to the organisation's risk culture. }\end{array}$ \\
\hline $\begin{array}{c}\text { Systems } \\
\text { theory }\end{array}$ & $\begin{array}{c}\text { The organisation is a living organism with many } \\
\text { interdependent parts which have specific functions and } \\
\text { inter-connected responsibilities. (O'Hair et al., 2005) }\end{array}$ & $\begin{array}{c}\text { Risk culture and organisational performance can be said to be } \\
\text { interdependent parts. In this study the assumption is that risk } \\
\text { culture affects organisational performance. }\end{array}$ \\
\hline
\end{tabular}

\section{Volume 4 Issue 12, December 2015}




\section{International Journal of Science and Research (IJSR) \\ ISSN (Online): 2319-7064}

Index Copernicus Value (2013): 6.14 | Impact Factor (2014): 5.611

\section{Conceptual Framework of the Study}

The conceptual framework of the study developed in line with the study's overall objective of establishing the effect of risk culture on organisational performance. Thus the independent variable was risk culture which had four sub variables. These sub variables were tone at the top, accountability, effective challenge and compensation. The dependent variable was organisational performance in financial institutions listed on the Ghana Club 100. In line with extant literature reviewed the dependent variable comprised two sub-variables. These were financial and nonfinancial indicators. Below is a diagrammatical representation of the conceptual framework.

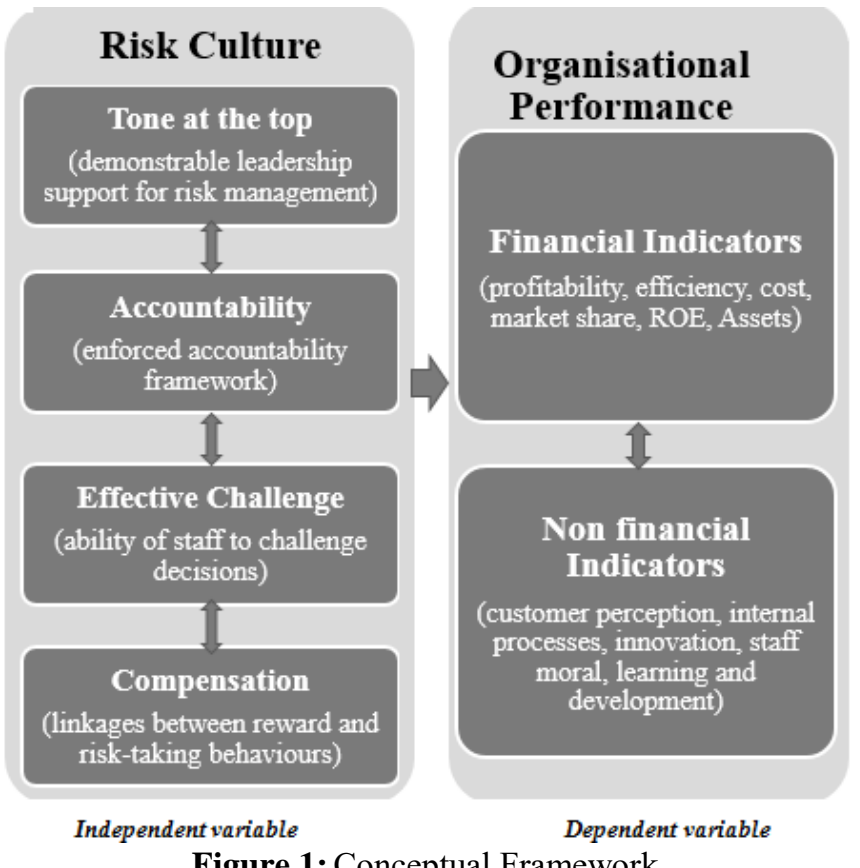

\section{Empirical Review}

Schalk (2008) points out that culture is always complex; multidirectional and members of a culture can never fully describe all of the beliefs that underpin their culture. He points out further that an organisation's culture is never fully unified. This thus implies that there are always subcultures including risk culture within the organisation. Risk culture or the overall risk management practices appears to be considered perhaps as one of the key subcultures of an organisation.

Deal and Kennedy (1982) for instance noted that a strong organisational culture is very valuable in enhancing employee performance which leads to the achievement of the overall performance of the organisation. Performance of employees is described as the "ability of employees to attain goals either personal or organisational by using resources efficiently and effectively" (Daft, 2000).

Also non-material culture including norms and values of organisational culture are believed to have significant effect on employee performance for that matter the performance of the organisation. According to Stewart (2010) these norms and values have a significant effect on the employee performance and the organisation's profitability. Thus Stewart (ibid) recommends that norms and value should be part of organisational culture.

Studies attempt to link organisational culture to the performance of the organisation. Several authors (Denison and Fey, 2013; Petty et al., 1995; Kotter and Heskett, 1992; and Denison, 1990) have sought to establish a relationship between organisational culture and performance. In a more recent study by Zakari et al., (2013) on the Banking Industry in Ghana, the study also drew linkages between an organisation's cultures and its performance. In fact they concluded that "organisational culture was overall found to be positively related to organisational performance".

Following the global financial crisis of 2008, a number of studies commissioned to investigate the corporate failures has also sought to draw linkages between risk culture and organisational performance. The Walker Report concluded that the principal causal agents in many cases were behaviour and culture (Walker, 2009). The European Commission also highlighted the "absence of healthy risk management culture" as the cause of the organisational failures (EC 2010).

According to Ashby et al. (2012), the concept of risk culture has grown steadily since the GFC of 2008. The term did not appear much in literature prior to the GFC. Risk culture is therefore an emerging terminology which encapsulates a company's risk appetite, tolerance and risk management practices as demonstrated by its employees. The risk appetite of a business is the total amount of risk an organisation is prepaid to take in pursuit of its value creation (KPMG, 2008), while risk tolerance refers to "the amount of uncertainty an organisation is prepared to accept in total" (Risk and Insurance Management Society, RIMS, 2012) to achieve its objectives.

The IRM definition of risk management implied that every business needs to take risks to achieve its objectives and fulfil its vision. Thus the existing risk culture within the organisation can enhance its risk management initiative or practices. An organisation's risk culture can greatly impact its capacity to take "strategic risk decisions and deliver on performance promises" (IRM, 2012). Defects in risk culture is therefore seen as a precursor to the business failures documented by various commentators on the corporate failures leading to the global economic crisis, (Walker, 2009; House of Commons Treasury Committee, 2009). The IIF stated further that "the crisis had provided clear evidence that effective cultivation of a consistent risk culture throughout firms is the main enabling tool in risk management" (IIF 2009).

The IIF (2008) also concluded that; "the development of a risk culture throughout the firm is perhaps the most fundamental tool for effective risk management". Farrel and Hoon (2015) also came to the conclusion that an organisational risk culture is a crucial factor which helps to ensure that doing what is right triumphs over doing whatever it takes. To support this assertion they cited a recent KPMG survey which covered almost 500 bank executives.

\section{Volume 4 Issue 12, December 2015}




\section{International Journal of Science and Research (IJSR) \\ ISSN (Online): 2319-7064 \\ Index Copernicus Value (2013): 6.14 | Impact Factor (2014): 5.611}

The survey revealed that almost half ( 48 percent) of respondents indicated risk culture as a leading contributor to the credit crisis. Institutions with a strong risk culture history managed to weather the storm. More than half ( 58 percent) of corporate Board members and internal auditors surveyed by the survey said that their company's employees had little or no understanding of how risk exposures should be assessed for likelihood and impact. One-third of the respondents also mentioned that key leaders in their organisation had no formal risk management training or guidance.

It is safe to conclude from the literature review that although risk culture is becoming an important business management topic, many organisations demonstrate deficiencies in this area. Farrel and Hoon (2015), argue that business executives should pay more attention to risk culture. They contended that, "organisations with inappropriate risk cultures will inadvertently find themselves allowing activities that are totally at odds with stated policies and procedures or operating completely outside these policies".

According to the IRM (2012) many organisations are paying a greater attention to risk and risk management following the GFC. Increasingly it is being understood that developing a healthy risk culture results in dividends. The important question therefore to be asked was put forward by the IRM. It asks whether risk culture is effectively supporting or undermining the longer-term success of the organisation (IRM, 2012). It is therefore logical to deduce that risk culture affects the performance of organisations.

\section{Research Gaps}

From the literature reviewed it is evident that risk culture has become an important subject in the sustainable value creation venture of organisations. Failures in risk culture were seen as the root cause of the GFC. Understanding risk culture therefore is critical to future performance of organisations. Various measures or determinants of risk culture were reviewed including that postulated by the FSB. These are tone at the top, accountability, effective challenge and compensation. The researcher relied on these measures to assess the risk culture of the organisations covered in the sample population.

Another issue the literature tried to address is the measurement of organisational performance. It was identified that there continues to be no conclusive study that has identified a "best" criterion for measuring organisational performance (Carton 2004). To achieve a balanced result within the limited time of the research, the study relied on the assessment criteria used by the Ghana Club 100 and incorporated the non-financial elements of the BSC.

It is also important to note that none of the prior works reviewed on risk culture was done in Ghana or other comparable jurisdictions. Risk culture in Ghanaian organisations has not been studied prior to this work. This study is therefore an attempt to address this gap and present an understanding on the risk culture of business organisations in Ghana.
The key task of the research is to examine the effect of risk culture on organisation performance. Thus the empirical review examined the relationship between these variables. The empirical evidence reviewed sought to suggest a relation between risk culture and organisation performance.

\section{Research Methodology}

To undertake an in-depth and credible research and comprehensively address the research aim and objectives, a post-positivist research philosophy was adopted, to allow for the use of methods most appropriate at different stages of the study (Patton, 1988). This allowed for the use of both qualitative and quantitative research approaches in the conduct of the research. Qualitative approach was used to seek an "understanding" of the factors or elements constituting the risk culture of companies (Williams, 2007). Quantitative approach was used to explain the relationship between risk and organisational performance.

The research design employed is the correlational field survey research which according to Tharenou et al. (2007) involves the administration of questionnaires to gather data to test a research question(s) and at the same time could also be used with other data collection techniques including interviews and observations. This design made it possible for the researcher to collect both quantitative and qualitative data to address the research questions appropriately.

The entire population of the study is the companies making the Ghana Club 100. A hundred (100) companies make up the Club at every given time (GIPC, 2015). However the targeted population for the study is all the 19 companies of the Club that are financial institutions or formal banks licenced by the central Bank of Ghana (BoG). The assessable population for the study includes these banks and their respective staff in risk management and related positions.

Given that the population considered for the study is finite, it means there is a reliable sampling frame from which the respondents will be selected. Management executive in risk and risk related positions are the actual respondents for the target population.

Purposive sampling is therefore adopted to select one respondent from each of the companies selected because not all staff in a company have the same level of information regarding the company's risk culture (Shaughnessy et al., 2011). Actual respondents are key risk management or related executives. In all, the total number of respondents were 19 risk management executives.

Structured questionnaire survey was the main research instrument used. This was however complemented with structured interviews to gain a fuller understanding of the issues responded to in the questionnaire and other issues that could not be captured on the questionnaire.

The research used content analysis to analyse the qualitative data collected, using predetermined categories of the research. This helped in identifying themes and patterns 


\section{International Journal of Science and Research (IJSR) \\ ISSN (Online): 2319-7064}

Index Copernicus Value (2013): 6.14 | Impact Factor (2014): 5.611

which assisted in the reporting of findings from the research (Bryman 2004). This allowed the sampled companies to be grouped on the basis of their respective risk cultures. Quantitative data collected was analysed using descriptive statistics. Completed questionnaires were coded and subsequently analyzed using Statistical Package for Social Sciences (SPSS version 22). Pearson Bivariate Correlational Technique was used to evaluate the relationship between risk culture variables and organisational performance.

\section{Results and Discussion}

\subsection{Determinants of Risk Culture}

The development and advancement of risk culture encompasses identifying and advancing the required areas and issues. The study, through the literature review identified four key measurable dimensions that are deemed relevant in the advancement of risk culture in an organisation (Tone at the top - Leadership; Accountability; Effective Change; Compensation).

Each dimension measurement is assessed with a number of positive statements characteristics which are deemed to prevail in an environment that embrace and promote effective risk culture. The study participants were to score each statement with point from 1 to 5 where $1=$ Strongly Disagree $2=$ Disagree $3=$ Neutral $4=$ Agree $5=$ Strongly Agree. The mean scores of the statements were computed for each dimension; the higher the mean scores the higher the dimension contributing determinant to risk culture and vice versa. Figure 4.5 illustrates the summary mean scores on each of the dimension.

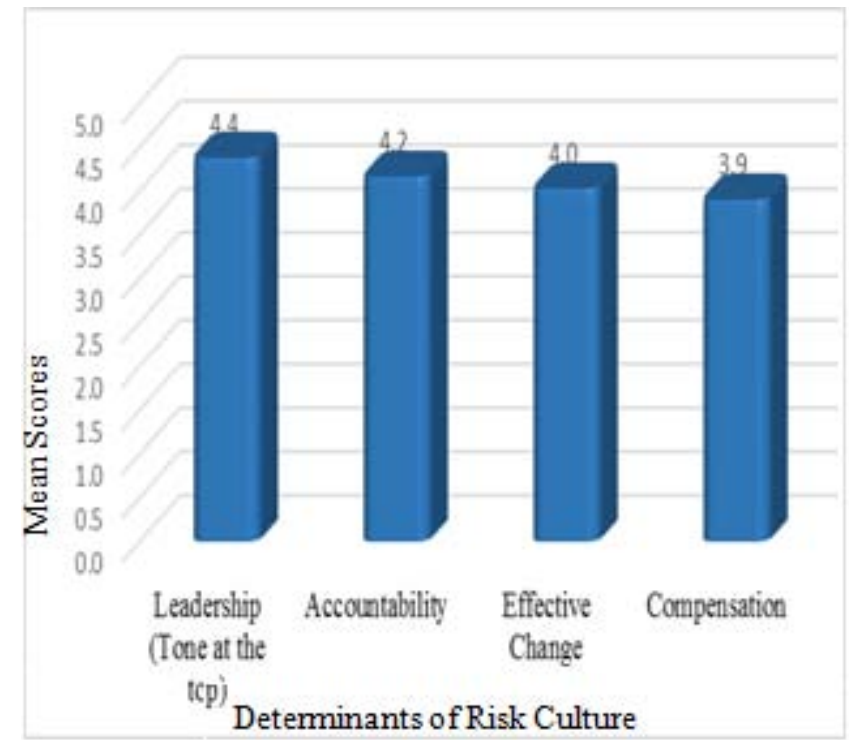

Figure 2: Mean Scores on the Determinant of Risk Culture Dimensions

Source: Field data

Observably, it can be seen that all the dimensions are key determinants of achieving positive risk culture in the surveyed companies. Leadership dimension is seen to be the highest determinant of risk culture whiles compensation is seen as the least component. It is also important to note that all respondents agreed with FSB (2013) that the four risk culture determinants are the main indicators of a strong risk culture in companies.

\subsection{Challenges to Developing Effective Risk Culture}

Challenges to developing effective risk culture was examined through the structured interview with respondents. Interviews were held with 11 out of the 19 total respondents representing almost $60 \%$ of the sample population. The responses were recorded by the researcher using a digital recorder. The recordings were further transcribed and content analysis was used to identify similar themes and trends.

Key themes identified as factors inhibiting the development of an effective risk culture were the total understanding of the company's overall value propositions strategy which drives its risk appetite and risk tolerance levels; leadership support and promotion of risk management; existing responsibility and accountability framework; the culture of silence and inability to challenge long held traditions, values and leadership positions; and to a lesser degree prevailing performance management systems. Except for the first thematic area mentioned above all the other areas correspond to the four risk culture determinants advanced by the FSB as cited in the literature reviewed.

Corresponding with the mean scores on the Determinants of Risk Culture in Figure 4.5, leadership action and inaction was mentioned as the most important challenge to developing an effective risk culture. This observation corresponds to Schein (1992) assertion that leadership perhaps is the most crucial in developing effective culture. Leadership action in the following areas identified by Schein were also mentioned.

- What leaders pay attention to - measure, control,

- Leaders reaction to critical incidents,

- Criteria for resource allocation,

- Role modelling, teaching, coaching,

- Observed way of allocating rewards and status,

- Observed criteria for recruitment, selection, promotion, retirement and excommunication.

\subsection{Relationship between of Risk Culture and Organisational Performance}

The analysis of the study examined whether advancement of risk culture contributes to organisational performance. A bivariate correlation analysis was conducted between the variables for the determinant of risk culture and that of organisational performance. The Pearson Correlation value measures the strength and direction of the linear relationship between two variables. A positive correlation coefficient indicate that an increase or decrease in one variable leads to an increase or decrease in the other comparing variable (that is move in the same direction). A negative correlation coefficient indicates that an increase or decrease in one variable leads to a decrease or increase in the other variable (that is, moving in opposite direction. Again, a high correlation (above absolute 0.5) is an indication of strong relationship between the two comparing variables. Similarly, 


\section{International Journal of Science and Research (IJSR) \\ ISSN (Online): 2319-7064 \\ Index Copernicus Value (2013): 6.14 | Impact Factor (2014): 5.611}

a low correlation value (below absolute 05 ) is an indication of a weak or no relationship between the two comparing variables.
The summary table below in table 4.7 provides the contingency table of the correlation output between variables of the determinant of risk culture and that of organisational performance.

Table 2: Correlation between indicators of the determinants of risk culture and that of organisational performance.

\begin{tabular}{|c|c|c|c|c|c|c|c|}
\hline & & Leadership & Accountability & \begin{tabular}{|l|} 
Effective \\
Challenge
\end{tabular} & Compensation & \begin{tabular}{|c|} 
Business \\
Performance \\
Financial \\
\end{tabular} & $\begin{array}{c}\text { Business } \\
\text { Performance } \\
\text { :Non-Financial }\end{array}$ \\
\hline \multirow{2}{*}{ Leadership } & Pearson Correlation & 1.00 & 0.57 & 0.61 & 0.31 & 0.38 & 0.03 \\
\hline & Sig. (2-tailed) & & 0.01 & 0.01 & 0.20 & 0.11 & 0.91 \\
\hline \multirow[t]{2}{*}{ Accountability } & Pearson Correlation & & 1.00 & 0.80 & 0.66 & 0.49 & 0.49 \\
\hline & Sig. (2-tailed) & & & 0.00 & 0.00 & 0.03 & 0.03 \\
\hline \multirow[t]{2}{*}{ Effective Challenge } & Pearson Correlation & & & 1.00 & 0.69 & 0.46 & 0.52 \\
\hline & Sig. (2-tailed) & & & & 0.00 & 0.05 & 0.02 \\
\hline \multirow[t]{2}{*}{ Compensation } & Pearson Correlation & & & & 1.00 & 0.48 & 0.55 \\
\hline & Sig. (2-tailed) & & & & & 0.04 & 0.02 \\
\hline \multirow[t]{2}{*}{$\begin{array}{c}\text { Business Performance: } \\
\text { Financial } \\
\end{array}$} & Pearson Correlation & & & & & 1.00 & 0.50 \\
\hline & Sig. (2-tailed) & & & & & & 0.03 \\
\hline $\begin{array}{c}\text { Business Performance: } \\
\text { Non-Financial }\end{array}$ & Pearson Correlation & & & & & & 1.00 \\
\hline
\end{tabular}

\section{Source: Field data}

It is observed from the correlation table above that, there exists significant relationship between the indicators being used for the determinant of risk culture and also between the risk culture dimension and that of organisational performance. This position is in agreement with existing literature. In fact culture has long been identified as having a positive relationship with organisational performance. In Ghana, Zakari et al., (2013) concluded that "organisational culture was overall found to be positively related to organisational performance". Other studies have also sought to draw linkages between risk culture and organisational performance. Notable among them were Walker (2009) and the EC (2010), which observed that the absence of healthy risk culture is the cause of organisational failures.

A unique relationship between the various risk culture determinants was identified. This finding is novel as no prior work was identified in this regard. Among the dimensions for the determinant of risk culture, leadership largely correlated to accountability and effective challenge while accountability is highly correlated with effective challenge and compensation. Considering the relationship between risk culture and organisational performance, the correlation output strongly confirms the existence of positive relationship between risk culture and business performance.

Specifically, there is significantly higher positive correlation between the risk culture and the non-financial organisational performance especially on the effective challenge and the compensation dimension. Even though the correlation between the risk culture dimension and that of the financial performance indicators are weak (below absolute 0.5), the corresponding $\mathrm{p}$-value for the correlation between accountability dimension and the financial performance and between compensation dimension and the financial performance are below the significant level of 0.05 or $5 \%$ which statistically confirms the existence of significant relationship (correlation of 0.49 with corresponding $p$-value of 0.03 and 0.48 with p-value of 0.04 respectively).

Conclusively, it can be said that, identifying and promoting the factors or dimension that advance risk culture also leads to promoting the factors that advance the organisational performance. In summary there is a high perceived positive effect of risk culture on all aspects of organisational performance.

\section{A Generic Framework for Developing Risk Culture in Organisations}

As demonstrated in the findings of the study the importance of an effective risk culture in achieving the desired organisational performance cannot be over emphasized. The findings of the study revealed that risk culture has a significant effect on organisational performance. It is therefore imperative to look up to risk culture as a means to achieving sustained organisational performance. As opined by Farrel and Hoon (2015), business executives should pay more attention to risk culture. Thus a generic framework to achieve the right risk culture in any company is a very laudable objective which this research sought to attain.

Based on the research findings, the following Risk Culture Framework (RCF) shown below has been developed. It is grounded on the extant literature on risk culture and responses gathered from the questionnaire and collaborated by the deeply held views identified during the structured interviews with the respondents. It highlights the building blocks needed to have a strong risk culture in all organisations.

The proposed risk culture framework is intended to serve as a strategic foundation for building an effective risk culture in all types of business. It is not envisioned for use "as is" but rather as a model or a guide for all business executives 


\section{International Journal of Science and Research (IJSR) \\ ISSN (Online): 2319-7064 \\ Index Copernicus Value (2013): 6.14 | Impact Factor (2014): 5.611}

working to build a risk culture that regulates the risk appetite, tolerance and actual practices needed to ensure the desired organisational performance that provides sustained value to the all the business stakeholders.

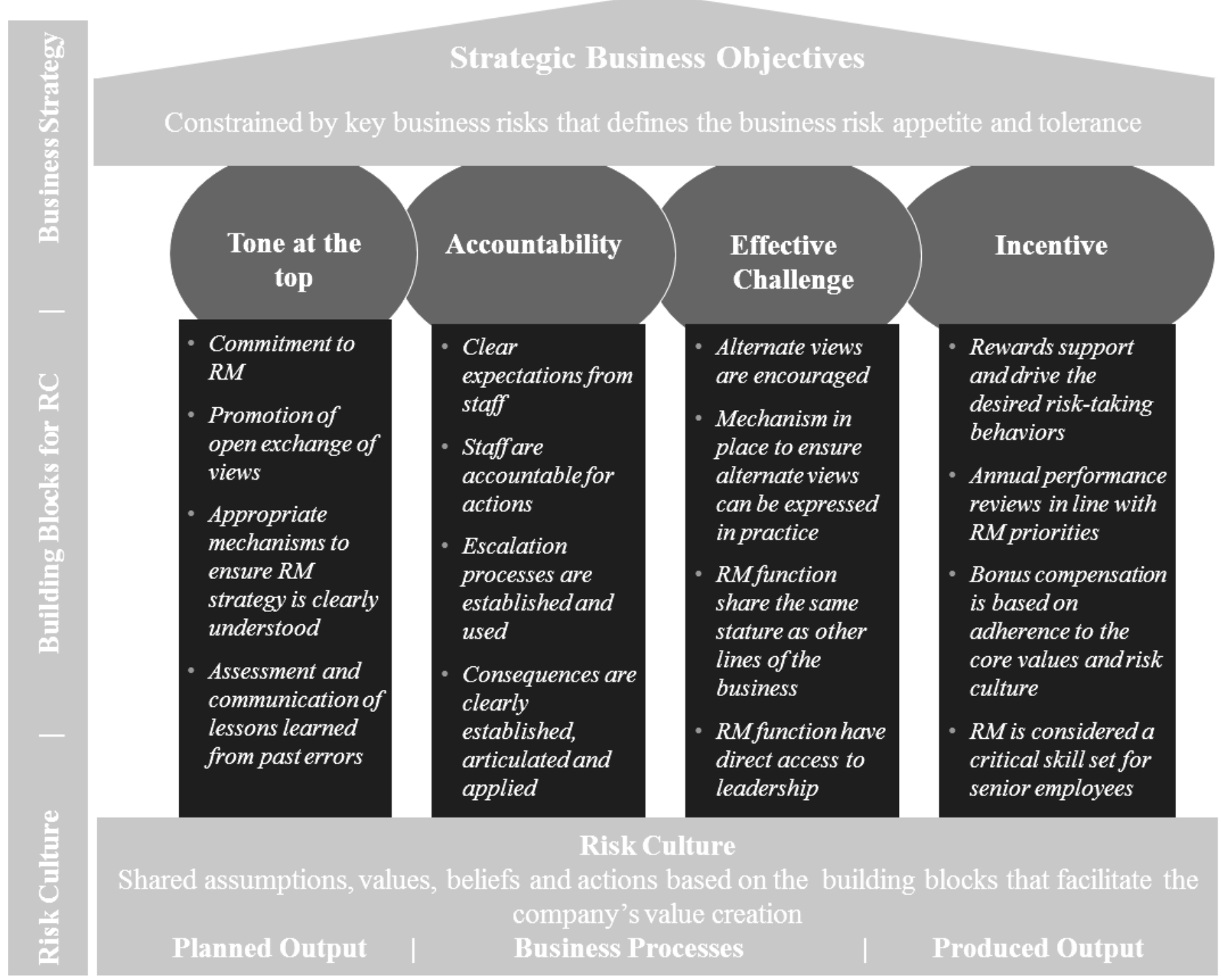

Figure 3: Generic Framework for Developing Risk Culture

Source: Author's Construct

\section{Implications of the Findings}

Perhaps the most important finding of the research project is that there is a high positive effect of risk culture on all aspects of organisational performance. This is in line with prior studies conducted after the GFC to establish the cause of the crisis (EC, 2010; Walker, 2009; House of Commons Treasury Committee, 2009; \& UK Parliamentary Commission on Banking Standards, 2013). A defective risk culture means a negative organisational performance. Risk culture is therefore an important variable in achieving sustained organisational performance.

Further risk management practices in organisations should be aimed at developing the appropriate behaviours instead of being a mere check box exercise. Indeed the purpose of any risk management programme should be aimed at building the right behaviours among the rank and file of the organisation (PwC, 2009). To achieve the desired risk culture in the organisation will however, require effort from all stakeholders. This includes top management, senior executives, functional managers and all staff.

Even though all hands must be on deck to achieve the desired risk culture in the organisation, the role of leadership cannot be overemphasized. Rightly, the research revealed that leadership action is crucial in developing effective risk culture in the organisation. Business leaders cannot overlook the impact of their role in creating the right risk culture. Without their overt involvement employees may see risk management practices as an additional burden imposed on them by management.

There is the need therefore for every organisation to examine its risk culture and establish it as the pillars on which performance is built. Without it performance is likely to be superficial and may come tumbling down in the face of the least shock in the system as experienced by the companies affected by the GFC. The importance of risk culture calls for every organisation to strive to achieve efficiency in this

\section{Volume 4 Issue 12, December 2015}




\section{International Journal of Science and Research (IJSR) \\ ISSN (Online): 2319-7064}

Index Copernicus Value (2013): 6.14 | Impact Factor (2014): 5.611

domain. This objective should change the stature of the risk management function in organisations from an operational unit to a strategic unit. Risk management should become the soul or perhaps also the spirit of the organisation with far reaching consequences from its actions and inactions on organisational performance.

It is also important to note that much research is needed in the area of risk culture to understand the phenomenon better and access its effects on organisational performance. For instance no research was identified in Ghana and other developing countries on the subject. Thus risk culture as a research area needs to be developed. Other researchers need to explore this domain. Especially the risk culture variables used for the study need further research to be established as the most reliable measures for risk culture.

\section{Recommendations}

In lieu of the research findings and implications, it is apposite to propose a number of recommendations for the consideration of business executives, risk management executives and other stakeholders as far as building effective risk culture for organisation performance is concerned. These recommendations include the following:

- There should be a deliberate attempt by business executives to promote the risk culture in the organisation. However every staff of the business must be involved in the development of an effective risk culture;

- Risk culture plays a critical role in organisation performance and must be considered when developing performance strategies;

- The business leadership especially top leadership including the board of directors must play an active role in the development of an effective risk culture;

- In examining the performance of businesses care must be taken not to exclude non-financial measures as these play a significant role in the overall and sustained performance of the business;

- Organisations should have in place performance indicators to evaluate the development of risk culture in the business;

- Developing an effective risk culture must always be done taking into account strategic value proposition of the business in question;

- The strategic value proposition of each business entity must drive its risk appetite, risk tolerance and overall risk management strategy.

\section{Recommendation for Further Studies}

This research has its own limitations as it cannot envelop all aspects of risk culture and organisational performance. Thus it is appropriate to turn these limitations into proposed future research projects. These future studies which will shed more light on critical areas of this research identified from the analysis and discussion of the study findings include:

- A future research project to investigate the dynamics of risk culture determinants across other fields of business such as manufacturing with a more focus on their influence on organisational performance will be a worth-while research undertaking;

- It also essential to examine the various risk management structures and practices across divers businesses. This phenomenon was not addressed in this study thus a research project to examine the various risk management structures and practices will be unique and apt;

- Having established the evidence of variables of risk culture and organisational performance, it will be appropriate that a further in-depth research is conducted on these each of these variables;

- Further investigation of the challenges to developing an effective risk culture in different organisations will help advance a holistic understanding of the factors affecting risk culture development;

- Investigation of the RCF from a theoretical perspective, considering lessons learned from other cultural change initiatives across other industries, with a view to refining, expanding or even discarding the Framework;

- Finally, investigation of the key indicators of RCF to discover the relative strength of each indicator in achieving the desired risk cultural change.

\section{References}

[1] S. Ashby, T. Palermo, M. Power. (2012). Risk culture in financial organisations: An interim report. Centre for Risk Analysis.

[2] E. Banks. (2012). Risk Culture: A Practical Guide to Building and Strengthening the Fabric of Risk Management, Palgrave Macmillan.

[3] Basel Committee on Banking Supervision. (2011). Sound Practices for the Management and Supervision of Operational Risk, Bank for International Settlements. Basel, Switzerland

[4] A. Bryman. (2004). Content Analysis in Social Research Methods, (p. 181). Oxford University Press. New York.

[5] R. B. Carton. (2004). Measuring Organisational Performance: An Exploratory Study. The University of Georgia, Athens, Georgia.

[6] R.L. Daft. (2000). Organization Theory and Design. (7th ed.) South-Western College Publishing, Thomson Learning. U.S.A.

[7] T.E. Deal, A.A. Kennedy, (1982). Corporate cultures: The Rites and Rituals of Corporate Life. Mass: AddisonWesley Publishing Co. Reading.

[8] D.R. Denison, C.F. Fey, (2013) Organizational Culture and Effectiveness: Can American Theory Be Applied in Russia? Retrieved April 13, 2015, from http://citeseerx.ist.psu.edu/viewdoc/download?doi=10.1. $1.202 .5968 \&$ rep $=$ rep1\&type $=$ pdf.

[9] D.R. Denison, (1990), Corporate culture and organisational effectiveness. John Wiley. New York.

[10] European Commission, (2010). Corporate governance in financial institutions and remuneration policies. Retrieved March 2, 2015, from http://ec.europa.eu/internal_market/company/docs/moder n/com2010_284_en.pdf.

[11]J.M. Farrel, A. Hoon, (2009). What's your company Risk Culture? National Association of Corporate Directors Directorship, April 15, 2009. 


\section{International Journal of Science and Research (IJSR) \\ ISSN (Online): 2319-7064}

Index Copernicus Value (2013): 6.14 | Impact Factor (2014): 5.611

[12] GIPC (2015) Ghana Club 100 - Ranking Criteria. Retrieved April 4, 2015, from http://www.gipcghana.com/about-gc-100/rankingcriteria.html.

[13] R.E. Hoyt, D.L. Moore, A.P. Liebenberg. (2006). The value of enterprise risk management: evidence from the US insurance industry. Retrieved July 5, 2011, from http://www.aria.org/meetings/2006papers/Hoyt_Liebenb erg_ERM_070606.pdf.

[14] IIF (2008). Financial services industry response to the market turmoil of 2007-2008, Institute of International Finance. Washington DC.

[15] IIF (2009). Risk culture. Institute of International Finance. Washington DC.

[16]IRM. (2012). Risk culture: Guidance from the Institute of Risk Management. Institute of Risk Management. London.

[17] M. Jensen, W. Meckling. (1976). Theory of the firm: managerial behavior, agency costs and ownership structure. Journal of Financial Economics 3, 305-360.

[18] J.P. Kotter, \& J.L. Heskett (1992). Corporate culture and performance. Macmillan, New York

[19] KPMG, (2008). Understanding Risk Appetite. Retrieved March 16, 2015, from https://www.kpmg.com/CN/en/IssuesAndInsights/Article sPublications/Documents/Risk-appetite-O-200806.pdf.

[20]B.W. Nocco, R.M. Stulz. (2006). Enterprise risk management: theory and practice. Journal of Applied Corporate Finance, 18(4): 8-20.

[21]D. O’Hair, G.W. Friedrich, L.D. Dixon. (2005). Strategic Communication in Business and the Professions, Pearson Education Limited. USA.

[22] Parliamentary Commission on Banking Standards. (2013a). An Accident Waiting to Happen: The Failure of HBOS. House of Commons Paper 705, Stationery Office Ltd. London.

[23] M. Q. Patton. (1988). Paradigms and pragmatism in D. M. Fetterman, Qualitative approaches to evaluation in education: the silent scientific revolution (pp. 116-137). Praeger. N.Y.

[24]R.E. Petty, C.P Haugtvdt, S.M. Smith. (1995). Elaboration as determinant of attitude strength. Creating attitudes that are persistent, resistant, and predictive of behavior. Lawrence Erlbaum Associates, Inc. Hillsdale, NJ.

[25] Risk and Insurance Management Society, RIMS Inc. (2012). Exploring Risk Appetite. Retrieved March 2, 2015, from https://www.rims.org/resources/ERM/Documents/RIMS Exploring_Risk_Appetite_Risk_Tolerance_0412.pdf.

[26] $\bar{H}_{\text {. Sant, }}(2010)$. Legal Risks in Financial Markets. Oxford University Press. London.

[27] Schalk (2008). Effects of market orientation on business performance: Empirical evidence from Iceland. Journal of Marketing and International Business. Retrieved on May 2, 2015, from https://notendur.hi.is/th/MSritgerdir/ritgerdir/ArtSchalk. pdf.

[28]E. H. Schein. (1992). Organizational Culture and Leadership (2nd ed.). Jossey-Bass, San Francisco.

[29]E. H. Schein. (2012). Corporate Culture. MIT Sloan School of Management, Cambridge.
[30] J. Shaughnessy, B. Zechmeister, S. Zechmeister. (2011). Research Method in Psychology. Ninth edition, McGraw-Hill, New York.

[31]E. Sheedy, B. Griffin. (2014). Empirical Analysis of Risk Culture in Financial Institutions. Interim Report.

[32]D. Stewart. (2010). Growing the Corporate Culture. Retrieved April 3, 2015, from https:/www.wachovia.com/foundation/v/index.jsp?vgne xtoid=ab411f07760aa110VgnVCM1 000004b0d1872 RCRD\&vgnextfmt $=$ default.

[33]P. Tharenou, R. Donohue, B. Cooper. (2007). Management Research Methods.

[34] S. Waddock. (May 2005). Hollow Men and Women at the Helm, Hollow Accounting Ethics. Issues in Accounting Education, Vol. 20, No. 2, pp. 145-150.

[35] D. Walker. (2009). A Review of Corporate Governance in UK Banks and other Financial Entities: Final Recommendations, HM Treasury, London.

[36] Williams, C. (2007). Research Methods. Journal of Business \& Economic Research, 65-71.

[37]M. Zakari, K. Poku, W. Owusu-Ansah. (2013). Organisational Culture and Organisational Performance: Empirical Evidence from the Banking Industry in Ghana. International Journal of Business, Humanities and Technology, Vol. 3 No. 1

\section{Author Profile}

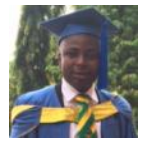

Benjamin Kpodo holds a Master of Philosophy in Business Consulting and Enterprise Risk Management from the Kwame Nkrumah University of Science and Technology and a Bachelor of Arts (Hons) from the University of Ghana, Legon. He has extensive experience as a risk management practitioner and a business consultant. Presently he is the Country Risk and Quality Manager for PricewaterhouseCoopers (Ghana) Limited.

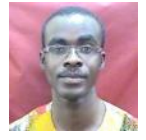

Kofi Agyekum is an assistant lecturer at the Department of Building Technology, Kwame Nkrumah University of Science and Technology. He holds a Doctor of Philosophy; Master of Philosophy; and a Bachelor of Science (Hons) in Building Technology from the Kwame Nkrumah University of Science and Technology with extensive experience across all areas of Construction materials. He is currently the Assistant Examination Officer of the Department and a Coordinator for Regular and Distance learning integrated project works due to his excellence and hard work. 